Grand Valley State University

ScholarWorks@GVSU

$12-2003$

\title{
Exploring Contraceptive Pill Taking Among Hispanic Women in the United States
}

\author{
Joseph W. Brown \\ University of Michigan - Ann Arbor, winbrown@umich.edu \\ Antonia M. Villarruel \\ University of Michigan - Ann Arbor \\ Deborah Oakley \\ University of Michigan - Ann Arbor \\ Carmen Eribes \\ Grand Valley State University
}

Follow this and additional works at: https://scholarworks.gvsu.edu/kcon_articles

\section{ScholarWorks Citation}

Brown, Joseph W.; Villarruel, Antonia M.; Oakley, Deborah; and Eribes, Carmen, "Exploring Contraceptive Pill Taking Among Hispanic Women in the United States" (2003). Peer Reviewed Articles. 10.

https://scholarworks.gvsu.edu/kcon_articles/10

This Article is brought to you for free and open access by the Kirkhof College of Nursing at ScholarWorks@GVSU. It has been accepted for inclusion in Peer Reviewed Articles by an authorized administrator of ScholarWorks@GVSU.

For more information, please contact scholarworks@gvsu.edu. 


\title{
Exploring Contraceptive Pill Taking Among Hispanic Women in the United States
}

\author{
Joseph W. Brown, PhD \\ Antonia M. Villarruel, $\mathrm{PhD}$ \\ Deborah Oakley, PhD \\ Carmen Eribes, $\mathrm{PhD}$
}

\begin{abstract}
Data from the 1995 National Survey of Family Growth have previously shown greater risk of inconsistent contraceptive pill use among Hispanic women. We used the same data to test a culturally based model of pill use among the subsample of Hispanic women. Hierarchical logit analyses revealed that primary use of Spanish, negative attitudes about women in the workplace, two or more recent sex partners, and recent pill adoption were factors that increased the odds of inconsistent use. Living alone or with non-kin was associated with more consistent use, as were showing preference for a stay-at-home model of motherhood, frequent church attendance, and frequent sexual intercourse. Our findings suggest that the strong effects of behavioral variables (e.g., duration of pill use, number of sex partners) are mediated by cultural indicators (e.g., primary use of Spanish, attitudes about sex roles). The extent to which programs address important cultural dimensions of health behaviors could enhance effectiveness.
\end{abstract}

Keywords: Hispanics; Latinas; contraception; culture

Almost half of unintended pregnancies in the United States occur during a month in which women report using a reversible method of contraception. ${ }^{1}$ The single most popular reversible method to prevent pregnancies is the contraceptive pill. According to the most recent national data, $27 \%$ of all women practicing contraception, or 44 million women, used the pill. ${ }^{1}$ Although the proportion of unintended pregnancies among this population is not known, the Food and Drug Administration (FDA)-mandated instructions for oral contraception note that inconsistent use of the pill can lead to unintended pregnancies.

Recent findings show that inconsistent use of the pill was 2.5 times more likely to occur among Hispanic women than among others sampled in Cycle $\mathrm{V}$ of the National Survey of Family Growth (NSFG-V). ${ }^{2}$ (As with most surveys conducted at the federal level, the term Hispanic is used in the original data. We follow this nomenclature to be

Joseph W. Brown, School of Public Health, University of Michigan, Ann Arbor. Antonia M. Villarruel and Deborah Oakley, School of Nursing, University of Michigan, Ann Arbor. Carmen Eribes, School of Nursing, Grand Valley State University, Allendale, Michigan.

Address reprint requests to Joseph W. Brown, Department of Health Behavior and Health Education, School of Public Health, University of Michigan, 1420 Washington Heights, Ann Arbor, MI 48109-2029; phone: (734) 763-4320; fax: (734) 763-7379; e-mail: winbrown@umich.edu.

Partial support for this analysis was provided by the Centers for Disease Control and Prevention (CDC) Contract 0990-0115.

Health Education \& Behavior, Vol. 30 (6): 663-682 (December 2003)

DOI: $10.1177 / 1090198103256743$

() 2003 by SOPHE 
consistent with other reports from NSFG-V.) This is significant because Hispanic women are more likely than other women to rely on the pill to prevent pregnancy, and more than $30 \%$ of recent births to Hispanic women are characterized as unplanned. ${ }^{1}$ More consistent use of the pill would almost certainly help Hispanic women to avoid unintended pregnancy.

The task here is to investigate whether inconsistent oral contraceptive use among Hispanics is attributable to cultural factors. This is important because the inclusion of cultural values, attitudes, and norms is a key strategy to enhance the acceptability and effectiveness of health education interventions in diverse groups, ${ }^{3,4}$ including cultural differences among groups of Hispanic women. ${ }^{5}$

Unfortunately, although most national surveys are designed to oversample Hispanic groups, the size and cost of these surveys limit the extent to which robust cultural indicators of health care outcomes can be obtained. In this analysis of inconsistent pill use, we expand the original framework used by Peterson et al. ${ }^{2}$ by exploring the influence of variables that were the best available measures of Hispanic ethnicity and culture in the NSFG-V. Our objective is to produce useful findings for health educators working with Hispanic populations in the area of pregnancy prevention.

\section{CONTRACEPTIVE PILL USE: A HISPANIC MODEL AND MEASURES}

In 2000, 32.8 million persons of Hispanic origin were living in the United States. Among this population, $66.1 \%$ were of Mexican origin, $14.5 \%$ were Central or South American, $9.0 \%$ were Puerto Rican, $4.0 \%$ were Cuban, and the remaining $6.4 \%$ were of other Hispanic origins (U.S. Census Bureau 2001). Despite this diversity, many studies either focus solely on Mexican Americans or pool Hispanics into a single aggregate group. This is a problem because sexual and contraceptive behaviors vary significantly among Hispanic women of different national origins. ${ }^{6-9}$

We investigate the extent to which primary language use, gender roles, and religion help to shed light on this variation. Although these measures obviously fall short of representing a full constellation of culturally specific influences, we use them here because they are available in the NSFG data set and because their efficiency as proxy measures has been demonstrated in other family planning studies. ${ }^{10}$ Moreover, these three constructs have been linked with sexual and contraceptive behavior across a range of Hispanic subgroups and are likely to be highly important in the development of culturally effective interventions (see Torres and Villarruel ${ }^{11}$ for a review of this research).

\section{Primary Language Use}

An impressive number of studies suggest that level of acculturation is associated with health behaviors and health outcomes, ${ }^{12,13}$ as well as attitudes about contraception. ${ }^{14}$ Consequently, researchers have developed indicators of acculturation based on multiple survey items. ${ }^{15,16}$ However, because the NSFG-V did not include any such measures, we use preference for Spanish language as a marker for a woman's adherence to traditional health views and practices. Primary use of Spanish has been associated with negative attitudes toward condom use, ${ }^{14,17}$ decreased prevalence of multiple partners, ${ }^{18}$ and lower AIDS risk among women ${ }^{19}$ compared to Hispanics whose primary language is English. Moreover, Marin et al. have shown that primary language use produced reliability and 
validity coefficients nearly identical to an acculturation scale developed from a much broader range of indicators. ${ }^{20}$ More recently, researchers have suggested that single indicators such as primary language might prove more efficient and useful than detailed indices to assess acculturation, especially for health education purposes. ${ }^{21}$

The NSFG-V interview was administered in the language of the respondent's choice, as recommended by Marín and Marín. ${ }^{22}$ For the NSFG-V, translation into Spanish was done with frequent interactions between the professional translation staff and bilingual NSFG staff. Special care was taken to select a dialect that would be understood and accepted among different Hispanic subgroups, including medical terms such as abortion. The resulting instrument was rigorously tested for ease of use as well as adequacy of the translation. ${ }^{23}$ Respondents chose the language of interview. If Spanish was chosen, the NSFG field staff arranged to have the interview administered by bilingual interviewers who had received additional training with the Spanish version of the questionnaire. We dichotomize language according to whether the interview was administered in Spanish or English.

\section{Gender Roles}

Gender roles among Hispanics are often associated with underlying premises about Hispanic male dominance and female submissiveness. Some argue that these gender roles are not unique to Hispanic culture but rather are detectable in a wide range of cultures, including Anglo culture in the United States. ${ }^{24}$ On balance, however, incorporating some measure of gender roles is important because of its centrality in studies of Hispanic health behavior. ${ }^{25}$ In particular, a woman's beliefs about the role of women in the family may affect her reproductive decision making. ${ }^{26}$ Indeed, studies have shown that gender roles have been linked with pro-natalist attitudes, ${ }^{27-29}$ low contraceptive use,${ }^{30}$ and higher pregnancy, birth, and marriage rates; ${ }^{28}$ prevalence of unprotected sex and multiple sexual partners ${ }^{30,31}$ formation of normative sexual behaviors $;{ }^{32}$ the likelihood of contraceptive use among Hispanic women; $; 1,33$ positive views of pregnancy and childbearing ${ }^{6,34}$ and higher unintended pregnancy, birth, and marriage rates. ${ }^{35}$

No direct measures are available in the NSFG-V. However, the questionnaire included 18 items designed to elicit attitudes on family life and the status and rights of women. These items derive from the work of Scanzoni, ${ }^{36}$ and each asks whether the respondent strongly agrees, agrees, disagrees, or strongly disagrees with a statement about gender roles. From the 18 items, we selected a priori 6 that were focused on a woman's role in the family and another 6 that asked about a woman's role in the workplace. Principal factor analysis then revealed eigenvalues strongly suggesting that the 12 selected items were differentiated into two gender role factors. Factor loadings were then used to reduce the pool of items to the three that best defined each factor. ${ }^{37}$

The first measure indicates preference for a more traditional "stay-at-home" model of motherhood, based on a respondent's level of agreement with the following three items $($ Cronbach's alpha $=.63)$ : First, "A pre-school child is likely to suffer if his mother works." Second, "A working mother can establish just as warm and secure a relationship with her children as a mother who does not work." Third, "Women are much happier if they stay at home and take care of their children." The measure indicates the proportion of respondents who agreed with the first statement (48\%), disagreed with the second (25\%), and agreed with the third (32\%).

The second gender role measure is based on three statements that are worded to reflect positive attitudes about a woman's right to have a career (Cronbach's alpha $=.64)$. First, 
"A woman should have exactly the same job opportunities as a man." Second, "A woman should not let bearing and rearing children stand in the way of a career if she wants it." Third, "A woman's job should be kept for her when she is having a baby." Our measure indicates the proportion that disagreed with the first (5\%), second (18\%), and third items (4\%). Such a response pattern can be associated with a more traditional attitude about a woman's role in the workplace. The correlation coefficient between the two gender role measures was significant at the $95 \%$ confidence level $(r=-.091)$.

\section{Religion}

Although the role of religion is widely considered as an essential element of Hispanic culture, ${ }^{38}$ relatively few empirical studies of sexual and contraceptive behavior among Hispanics have included multiple indicators of religion. ${ }^{14,26}$ More commonly, a measure of Catholic affiliation is used as a general marker for less permissive, more traditional sexual attitudes and behaviors. ${ }^{14,21}$ An exception is DuRant et al. ${ }^{39}$ who found that adolescent Hispanic women with no religious affiliation and infrequent church attendance were significantly more likely to have engaged in early sexual activity. Their study also showed that religious affiliation and practice differed significantly among Hispanic subgroups. Although more in-depth measures have been suggested, ${ }^{40}$ we also focus on religious affiliation and frequency of attendance at religious services.

A model describing the relation between pill use and a set of factors influenced by Hispanic ethnicity and culture is shown in Figure 1. In particular, we hypothesize that age, education, living arrangement, and whether the respondent is Mexican American comprise a set of demographic variables that influence the relative strength of Hispanic culture in the model. Hispanic culture is indicated by whether the interview was conducted in Spanish, by respondent scores on indices of gender role attitudes, and organizational religiosity. These cultural variables, in turn, affect the extent to which the interrelationship between sexual initiation, sexual behavior, and contraceptive behavior influences inconsistent use of oral contraceptives.

Dependent Variable. The dependent variable is a measure of inconsistent use of the pill. As in the study by Peterson et al., women who reported having missed two or more pills during the last 3 months of oral contraceptive use were classified as inconsistent users. ${ }^{2}$ Those who said they had missed none or one pill were classified as consistent users. This classification is based on FDA instructions, which warn that women who miss two or more pills in a row may be at increased hormonal risk. Although NSFG-V respondents did not specify whether missed pills were sequential, research suggests that an occasional missed pill is not a remarkable event, cognitively. ${ }^{41}$ Moreover, based on unpublished qualitative research by one of the coauthors (Oakley) to propose improved items for NSFG-VI, women who self-report missing two or more pills are very likely to have missed them sequentially.

Sociodemographic Variables. We control for age, schooling, living arrangement, and Hispanic origin. Age was categorized into three groups (15 to 19, 20 to 24, 25 to 44) in order to replicate the measurement used by Peterson et al. ${ }^{2}$ Schooling was dichotomized into those having at least a high school education versus those who have had fewer than 12 years of education. We examined living arrangement because of its suggested influence on sexual and contraceptive behavior. ${ }^{7,39}$ In particular, Soler et al. found that unmarried women who were not cohabiting with a sexual partner were 1.7 times more likely to 


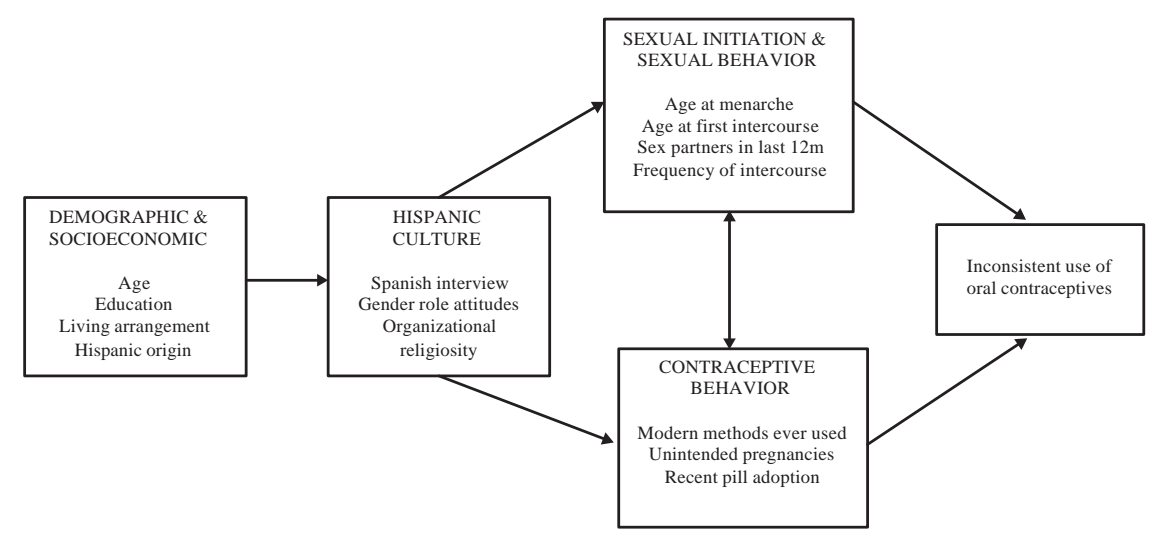

Figure 1. Path diagram of the determinants of inconsistent oral contraceptive use among Hispanic women aged 15 to 44: 1995 National Survey of Family Growth $(N=703)$.

a. As with most surveys conducted at the federal level, the term Hispanic is used in the original data. We follow this nomenclature to be consistent with other reports from the National Survey of Family Growth-Cycle V (NSFG-V).

b. Age at first intercourse in this study includes only those reports of intercourse that were considered "voluntary."

use contraception sporadically. ${ }^{42}$ Hispanic origin was indicated by whether the respondent was Mexican American or of other background (see sample characteristics).

Sexual Initiation and Sexual Behavior. This block of variables includes age at menarche, age at first intercourse, number of sex partners, and coital frequency. We include age at menarche because earlier ages have been shown to predict sexual initiation among Hispanic adolescents. ${ }^{7,27,39}$ Our measure is dichotomous, indicating whether menarche occurred at or before age 11. Early age at first intercourse (i.e., age 15 or younger) could indicate a longer period of exposure to the learned behavior of effective contraceptive use or, on the other hand, a propensity to engage in risky behaviors including less effective contraceptive use. Early initiation could also represent some degree of willingness to go against prevailing norms of sexual behavior (i.e., age at first intercourse in this study includes only those reports of intercourse that were considered "voluntary").

We also measure whether a respondent reports multiple sex partners (i.e., two or more) in the 12 months before the interview because this has been shown to predict poor oral contraceptive compliance among adolescents. ${ }^{43}$ Multiple sex partners have been associated with increased use of the condom among Hispanic youths ${ }^{44}$ and with a lack of regularity in one's sexual life that increases the likelihood of inconsistent oral contraceptive use. ${ }^{45} \mathrm{We}$ also include frequency of intercourse because there is some evidence that compared to others, Hispanic women report less frequent sexual intercourse, ${ }^{8}$ although the relationship between coital frequency and oral contraceptive consistency remains unclear. We explore whether frequent intercourse leads to more consistent pill use, based on the idea that among women having intercourse four or more times per week, consistent pill taking might represent a more salient issue.

Contraceptive Behavior. A respondent's contraceptive history may have some influence on her contraceptive behavior just prior to the 1995 NSFG interview. Specifically, 
because of the greatly increased awareness of HIV and other sexually transmitted infections during the late 1980s and early 1990s, an increasing percentage of women whose partners used the condom were also users of the pill or other methods. ${ }^{46,47}$ Such safer sex practices might therefore be associated with a tendency to switch between hormonal and barrier methods in an attempt to negotiate the dual risks of infection and pregnancy. Consequently, this switching behavior could indicate a propensity to use the pill more carefully. To test this idea, we include a measure indicating whether a respondent had used three or more modern methods in the 24 months prior to the NSFG-V interview. Finally, Peterson et al. found only two significant predictors other than race/ethnicity: (1) having had at least one unintended pregnancy and (2) having used the pill for a duration of only 3 to 6 months prior to the interview. ${ }^{2}$ We include the same two predictors in this analysis.

\section{METHOD}

\section{Sample}

The sampling frame used for the NSFG-V was adapted from the 1993 National Health Interview Survey (NHIS), a multistage household survey covering the noninstitutionalized civilian population of the United States through 198 primary sampling units that included all of the largest metropolitan areas and counties in nearly every state. A total of 10,847 women were interviewed in 1995 between the months of January and October. Hispanic and non-Hispanic Black women were selected with higher probability than were other women so that more reliable statistics for these groups could be estimated. The response rate for all women aged 15 to 44 was $78.6 \%$, and $79.5 \%$ for Hispanic women. Interviews averaged 103 minutes in length and were conducted in the homes using laptop computers. As will be discussed in the next section, sampling weights were developed by the NSFG-V staff to adjust for the complex survey design, ${ }^{48}$ and consequently all figures presented in this study are weighted estimates. Variables used for the analyses presented here were created from the approximately 315 variables that were recoded by the NSFG-V staff, for which all missing values were imputed. However, overall item nonresponse was low due to the use of computer-assisted personal interview procedures (see Potter et al ${ }^{48}$ for a detailed discussion of imputation used in the NSFG-V).

During a contraceptive history, women who had used the pill in at least 1 of the 3 calendar months before the interview were asked, "During (the past 3 calendar months), how many pills that you were supposed to take did you miss?" The response categories included none, one, and two or more (nonhormonal pills, for the placebo week, were not included). The analysis presented here adopts the same exclusion criteria used in the earlier analysis. ${ }^{2}$ That is, the study group included only those who had used the pill in all 3 calendar months prior to the interview and had sex during that time period and who selfidentified as Hispanic. A total of 164 women met all three criteria; for the remainder of this study, we apply the sampling weights to this figure $(N=703)$.

\section{Statistical Analysis}

The conceptual model presented earlier proposes that inconsistent oral contraceptive use is affected by two blocks of proximate variables: (1) sexual initiation and sexual behavior and (2) contraceptive behavior. The effects of these proximate variables will presumably vary by elements of Hispanic culture. To test this hypothesis, we first exam- 
ined the bivariate association between each of the explanatory variables and inconsistent pill use. After this, the multivariate analysis used a hierarchical approach that allows the estimation of both direct and indirect effects of covariates. Finally, to explore relationships between key independent variables, we conducted separate logistic regression models using significant covariates from the full multivariate analysis as dependent variables. All analyses applied the NSFG-recommended weights and used the STATA svy estimators $^{49}$ to account for the multistage cluster design of the NSFG sample.

\section{RESULTS}

The results are presented in three parts. First, selected background characteristics are shown to provide a more detailed picture of this sample. Next, we show the proportion of women who missed two or more pills in the 3 months prior to the interview by each study variable. Finally, results from the multivariate analysis are presented, followed by supplemental analyses that explore relationships between significant independent variables.

\section{Sample Characteristics}

Table 1 shows that this sample of Hispanics is an accurate reflection of recent national estimates. Specifically, $62 \%$ of the sample is of Mexican origin. Puerto Ricans comprise $13 \%$ of the sample, Cuban Americans comprise 6\%, and the remaining 19\% consist of Hispanics from all other origins. Overall, $38 \%$ of the sample was born outside the United States, and 20\% were interviewed in Spanish. Respondents who self-identified as nonWhite include $11 \%$ of Mexican Americans, nearly $20 \%$ of Puerto Ricans, and about $22 \%$ of Hispanics from other origins. The sample as a whole tends to reside in urbanized areas, and its regional distribution is reflective of the actual distribution of Hispanics in the United States. Mexican Americans, for example, are heavily concentrated in the West, and Puerto Ricans in the Northeast. Similarly, more than half of all Cuban American respondents reside in the Midwest or South region, which includes the state of Florida.

\section{Bivariate Analysis}

With respect to the first block of variables, Hispanic women who are living alone or with nonfamily members (i.e., roommates or friends) are significantly less likely than Hispanic women in other arrangements to use the pill inconsistently (Table 2). In particular, $12.59 \%$ of women in nonfamily living arrangements had missed two or more pills in the 3 months prior to the interview compared with women in other arrangements. As for the variables indicating Hispanic culture, $7.14 \%$ of women whose responses indicated a preference for a "stay-at-home" model of motherhood reported inconsistent pill use, compared with nearly $40 \%$ of women who indicated negative attitudes about women pursuing a career reported inconsistent pill use. Catholics were less likely to report missing two or more pills (19.68\%) than other religious affiliations, whereas atheists were more likely $(58.11 \%)$. Finally, $53.06 \%$ of those never attending religious services had used the pill inconsistently, compared to $12 \%$ of those women who reported attending religious services frequently.

Table 2 also shows that women whose first intercourse occurred at age 15 or younger were more likely to use oral contraceptives inconsistently (45.96\%), compared with women whose first intercourse occurred later. It also reveals that $62.50 \%$ of women who 
Table 1. Selected Characteristics of Sexually Active Hispanic Women Aged 15 to 44 Who Used the Pill in Each of the 3 Months Prior to Interview, by Hispanic Origin: 1995 National Survey of Family Growth $(N=703)^{\mathrm{a}}$

\begin{tabular}{|c|c|c|c|c|c|}
\hline & $\begin{array}{c}\text { Mexican } \\
n=436\end{array}$ & $\begin{array}{c}\text { Puerto Rican } \\
\quad n=88\end{array}$ & $\begin{array}{l}\text { Cuban } \\
n=42\end{array}$ & $\begin{array}{c}\text { Other } \\
n=137\end{array}$ & $\begin{array}{c}\text { Total } \\
N=703\end{array}$ \\
\hline Born outside of the United States & $\begin{array}{l}37.04 \\
(4.66)\end{array}$ & $\begin{array}{c}37.50 \\
(12.14)\end{array}$ & $\begin{array}{c}50.00 \\
(17.73)\end{array}$ & $\begin{array}{l}40.63 \\
(8.71)\end{array}$ & $\begin{array}{l}38.41 \\
(3.81)\end{array}$ \\
\hline Interviewed in Spanish & $\begin{array}{l}23.15 \\
(4.07)\end{array}$ & 0.00 & 0.00 & $\begin{array}{l}25.00 \\
(7.68)\end{array}$ & $\begin{array}{l}20.12 \\
(3.14)\end{array}$ \\
\hline Non-White & $\begin{array}{l}11.11 \\
(3.03)\end{array}$ & $\begin{array}{l}18.75 \\
(9.79)\end{array}$ & 0.00 & $\begin{array}{l}21.88 \\
(7.33)\end{array}$ & $\begin{array}{l}13.41 \\
(2.67)\end{array}$ \\
\hline Lives in an MSA central city ${ }^{\mathrm{b}}$ & $\begin{array}{l}46.30 \\
(4.81)\end{array}$ & $\begin{array}{c}68.75 \\
(11.62)\end{array}$ & $\begin{array}{c}25.00 \\
(15.36)\end{array}$ & $\begin{array}{l}50.00 \\
(8.87)\end{array}$ & $\begin{array}{l}48.17 \\
(3.91)\end{array}$ \\
\hline Lives in the Northeast ${ }^{\mathrm{c}}$ & 0.00 & $\begin{array}{c}56.25 \\
(12.44)\end{array}$ & $\begin{array}{c}25.00 \\
(15.36)\end{array}$ & $\begin{array}{l}31.25 \\
(8.22)\end{array}$ & $\begin{array}{l}12.80 \\
(2.62)\end{array}$ \\
\hline Lives in the Midwest or South ${ }^{\mathrm{d}}$ & $\begin{array}{l}32.41 \\
(4.52)\end{array}$ & $\begin{array}{c}31.25 \\
(11.62)\end{array}$ & $\begin{array}{c}62.50 \\
(17.17)\end{array}$ & $\begin{array}{l}25.00 \\
(7.68)\end{array}$ & $\begin{array}{l}32.32 \\
(3.66)\end{array}$ \\
\hline Lives in the West ${ }^{\mathrm{e}}$ & $\begin{array}{l}67.59 \\
(4.52)\end{array}$ & $\begin{array}{l}12.50 \\
(8.29)\end{array}$ & $\begin{array}{c}12.50 \\
(11.73)\end{array}$ & $\begin{array}{l}43.75 \\
(8.80)\end{array}$ & $\begin{array}{l}54.88 \\
(3.90)\end{array}$ \\
\hline
\end{tabular}

NOTE: Standard errors are in parentheses.

a. Table is based on weighted data.

b. Respondent's address at time of interview classified according to 1990 census population counts. The U.S. Office of Management and Budget associates one or more central cities within each metropolitan statistical area (MSA).

c. The Northeast is composed of the following states: Maine, New Hampshire, Vermont, Massachusetts, Rhode Island, Connecticut, New York, New Jersey, and Pennsylvania.

d. The Midwest is composed of Ohio, Indiana, Illinois, Michigan, Wisconsin, Minnesota, Iowa, Missouri, North Dakota, South Dakota, Nebraska, and Kansas. The South is composed of Delaware, Maryland, DC, Virginia, West Virginia, North Carolina, South Carolina, Georgia, Florida, Kentucky, Tennessee, Alabama, Mississippi, Arkansas, Louisiana, Oklahoma, and Texas.

e. The West is composed of Montana, Idaho, Wyoming, Colorado, New Mexico, Arizona, Utah, Nevada, Washington, Oregon, California, Alaska, and Hawaii.

had two or more sex partners in the 12 months before the interview had used the pill inconsistently. Finally, women who reported having sexual intercourse four or more times per week were significantly less likely to have used the pill inconsistently $(8.22 \%)$.

The only significant bivariate predictor in the contraceptive behavior block was duration of pill use. Women whose use of the pill at the time of the NSFG-V interview was no longer than 6 months were much more likely to have used it inconsistently. Nearly $70 \%$ of these women had missed two or more pills in the last 3 months. Every use of three or more modern methods of contraception was not significantly associated with inconsistent use, nor was reporting one or more unintended pregnancies.

\section{Multivariate Analysis}

The multivariate analyses consist of three parts. First, results from the full hierarchical logistic regression analysis are presented and discussed (Table 3). Next, to obtain further insights concerning the indirect influences of culture on the consistency of pill use, each of the five significant cultural variables from the full model was entered as a dependent 
Table 2. Number of Sexually Active Hispanic Women Aged 15 to 44 Who Used the Pill in Each of the 3 Months Prior to Interview $(N=703)$, and Percentage Who Missed Two or More Pills in the Last 3 Months and Standard Errors, According to Selected Characteristics

\begin{tabular}{|c|c|c|c|c|}
\hline & $N$ & $\begin{array}{c}\% \text { Missed } \\
2+\text { Pills }\end{array}$ & $S E$ & $\begin{array}{c}95 \% \\
\text { Confidence } \\
\text { Interval }\end{array}$ \\
\hline \multicolumn{5}{|l|}{ Demographic and socioeconomic } \\
\hline \multicolumn{5}{|l|}{ Age } \\
\hline 15 to 19 & 85 & 32.94 & 11.61 & $14.50-58.72$ \\
\hline 20 to 24 & 167 & 28.74 & 7.95 & $15.54-46.93$ \\
\hline 25 to 44 & 451 & 22.39 & 6.14 & $12.37-37.10$ \\
\hline High school education & 467 & 23.79 & 5.19 & $14.88-35.75$ \\
\hline Lives with nonfamily members ${ }^{\mathrm{a}}$ & 143 & 12.59 & $5.60 *$ & $4.89-28.74$ \\
\hline Mexican origin & 436 & 24.31 & 4.74 & $16.01-35.11$ \\
\hline \multicolumn{5}{|l|}{ Hispanic culture } \\
\hline Interviewed in Spanish & 155 & 23.87 & 7.55 & $11.91-42.09$ \\
\hline Prefers stay-at-home motherhood & 98 & 7.14 & $5.41 *$ & $1.46-28.60$ \\
\hline Prefers male-centered workplace & 150 & 38.67 & $8.34 *$ & $23.64-56.22$ \\
\hline \multicolumn{5}{|l|}{ Religion } \\
\hline Catholic & 503 & 19.68 & $3.70 * *$ & $13.24-28.24$ \\
\hline Protestant & 103 & 24.27 & 10.36 & $9.30-50.05$ \\
\hline Other & 23 & 43.48 & 29.33 & $6.44-89.58$ \\
\hline Atheist/agnostic & 74 & 58.11 & $14.09 * *$ & $30.08-81.72$ \\
\hline \multicolumn{5}{|l|}{ Attendance of religious services } \\
\hline Never & 147 & 53.06 & $12.11 * *$ & $29.72-75.13$ \\
\hline 1 to 3 times a month or less & 331 & 21.75 & 6.62 & $11.24-37.90$ \\
\hline Once a week or more & 225 & 12.00 & $3.70 * *$ & $6.29-21.68$ \\
\hline \multicolumn{5}{|l|}{ Sexual initiation and sexual behavior } \\
\hline Menarche at age 11 or younger & 189 & 23.28 & 7.07 & $11.99-40.34$ \\
\hline First intercourse at age 15 or younger & 161 & 45.96 & $9.22 * *$ & $28.65-64.31$ \\
\hline $2+$ sex partners in last 12 months & 64 & 62.50 & $16.28 * *$ & $29.02-87.17$ \\
\hline Has intercourse $4+$ times per week & 73 & 8.22 & $5.80^{*}$ & $1.86-29.77$ \\
\hline \multicolumn{5}{|l|}{ Contraceptive behavior } \\
\hline Ever used $3+$ modern methods & 52 & 50.00 & 17.27 & $19.82-80.18$ \\
\hline One or more unintended pregnancies & 307 & 27.36 & 5.94 & $17.06-40.81$ \\
\hline Recent pill adopter (6 months or less) & 62 & 68.57 & $11.70 * * *$ & $42.13-86.74$ \\
\hline
\end{tabular}

a. Respondent is single (no spouse or partner is included in this living arrangement). $* p \leq .05 . * * p \leq .01 . * * * p \leq .001$.

variable and regressed on the sociodemographic indicators (Table 4). We then entered both the sociodemographic and cultural indicators in order to predict values of the significant sexual and contraceptive behavior variables (Table 5).

Hierarchical Logistic Regression. Model 1 of Table 3 reveals that controlling for age, completion of high school, and Mexican origin, living alone or with nonfamily members is significantly associated with inconsistent pill use. Specifically, the odds ratio (OR) of 0.34 tells us that the predicted odds of missing two or more pills in the last 3 months for women who live in nonfamily arrangements are 0.34 times the odds for women living in 
other arrangements. The design-based $F$ statistic of 1.59 for Model 1 indicates a poor fit of this sociodemographic model to the data.

When the variables representing Hispanic culture are added (Model 2), the $F$ statistic increases to 2.66 and indicates a statistically significant fit. In particular, the predicted odds of inconsistent use for women preferring stay-at-home motherhood are $14 \%$ of the odds for women who do not have this preference $(\mathrm{OR}=0.14)$. Second, respondents who indicated negative attitudes about women and careers are 4 times more likely to have used the pill inconsistently than their counterparts with less negative attitudes $(\mathrm{OR}=4.05)$. Third, women stating current Catholic affiliation are less likely to use the pill inconsistently than other women $(\mathrm{OR}=0.22)$. Finally, women who report attending religious services once a week or more were about $20 \%$ as likely to have used the pill inconsistently compared with women who attended less frequently $(\mathrm{OR}=0.19)$.

Model 3 of Table 4 shows the effects of including the sexual initiation and sexual behavior variables. Controlling for the effects of the sociodemographic and cultural indicators, three variables in this block were significant predictors of inconsistent use. Early age at first intercourse increased the odds of inconsistent use $(\mathrm{OR}=4.16)$, as did reporting two or more sex partners in the 12 months before the interview (OR $=8.37$ ). On the other hand, women who reported having intercourse four or more times per week were significantly less likely to miss pills than women for whom sexual intercourse is less frequent $(\mathrm{OR}=0.16)$. With a design-based $F$ statistic of 4.55 , Model 3 appears the best fit to the data. In other words, when the final block of variables was entered (contraceptive behavior), the overall fit is reduced slightly.

The full model (Model 4) highlights three important findings. First, having had one or more unintended pregnancies was not significantly associated with inconsistent use. Second, Model 4 shows that the odds of inconsistent pill use are significantly increased among women whose current duration of pill use is 6 months or less $(\mathrm{OR}=11.76)$. Third, when duration of pill use is entered into the regression model, the effects of early age at first intercourse lose statistical significance, whereas the effects of Spanish language become significant $(\mathrm{OR}=4.99)$.

Effects of Sociodemographic Variables on Culture. To obtain further insights concerning the indirect influences of Hispanic culture, we first used linear regressions to predict the four significant indicators of culture with only the sociodemographic variables entered as covariates (Table 4). As suggested by Table 4, having a high school education was inversely associated with a Spanish language interview $(\mathrm{OR}=0.49)$. Put differently, primary use of Spanish was more likely to occur among those without a high school education, controlling for the other sociodemographic covariates. This finding suggests that education has an indirect effect on inconsistent pill use through primary use of Spanish language. With respect to living arrangement, women residing with nonfamily members or roommates were 3.20 times more likely to use Spanish as a primary language. This suggests that in addition to direct effects, living in a nonfamily household has indirect effects on inconsistent use through primary use of Spanish.

Effects of Culture on Sexual and Contraceptive Behavior. The next panel of Table 4 shows the direct relationships between the significant covariates of sexual and contraceptive behavior. None of the Spanish interviewees reported having more than one recent sex partner, and the same was true for all respondents who indicated preference for the stayat-home model of motherhood. In addition, none of the frequent churchgoers reported 
Table 3. Odds Ratios From the Logistic Regression Analysis Showing the Effects of Sociodemographic Characteristics, Culture, Sexual Behaviors, and Contraceptive Use on the Odds of Missing Two or More Pills in the 3 Months Prior to Interview

\begin{tabular}{|c|c|c|c|c|}
\hline & $\begin{array}{c}\text { Model 1 } \\
\text { Sociodemographic Characteristics } \\
(d f=5)\end{array}$ & $\begin{array}{c}\text { Model } 2 \\
\text { Sociodemographic } \\
\text { Characteristics and Culture } \\
(d f=13)\end{array}$ & $\begin{array}{c}\text { Model } 3 \\
\text { Sociodemographic } \\
\text { Characteristics, Culture, } \\
\text { and Sexual Behavior } \\
(d f=17)\end{array}$ & $\begin{array}{l}\text { Model } 4 \\
\text { Full Model } \\
(d f=20)\end{array}$ \\
\hline \multicolumn{5}{|l|}{ Sociodemographic characteristics } \\
\hline \multicolumn{5}{|l|}{ Age } \\
\hline 15 to 19 & 1.68 & 0.67 & 0.29 & 0.41 \\
\hline 20 to 24 & 1.46 & 1.32 & 1.06 & 1.44 \\
\hline 25 to 44 (reference) & 1.00 & 1.00 & 1.00 & 1.00 \\
\hline High school education & 0.71 & 0.76 & 1.60 & 2.12 \\
\hline Lives with nonfamily members ${ }^{\mathrm{a}}$ & $0.34 *$ & $0.16^{* *}$ & $0.09 * *$ & $0.09 *$ \\
\hline Mexican origin & 0.81 & 0.76 & 0.70 & 0.85 \\
\hline \multicolumn{5}{|l|}{ Hispanic culture } \\
\hline Interviewed in Spanish & & 1.68 & 3.87 & $4.99 *$ \\
\hline Prefers stay-at-home motherhood & & $0.14 * *$ & $0.13 *$ & $0.12 * *$ \\
\hline Prefers male-centered workplace & & $4.05 * *$ & $4.90 * *$ & $4.60 * *$ \\
\hline \multicolumn{5}{|l|}{ Religion } \\
\hline Catholic & & $0.22 *$ & 0.35 & 0.72 \\
\hline Protestant & & 0.29 & 0.31 & 0.65 \\
\hline Other & & 0.37 & 0.39 & 0.05 \\
\hline Atheist/agnostic (reference) & & 1.00 & 1.00 & 1.00 \\
\hline \multicolumn{5}{|l|}{ Attendance of religious services } \\
\hline Never (reference) & & 1.00 & 1.00 & 1.00 \\
\hline 1 to 3 times a month or less & & 0.39 & 0.46 & 0.39 \\
\hline Once a week or more & & $0.19 * *$ & $0.25 *$ & $0.18^{*}$ \\
\hline
\end{tabular}




\begin{tabular}{|c|c|c|c|c|}
\hline & $\begin{array}{c}\text { Model } 1 \\
\text { Sociodemographic Characteristics } \\
(d f=5)\end{array}$ & $\begin{array}{c}\text { Model } 2 \\
\text { Sociodemographic } \\
\text { Characteristics and Culture } \\
(d f=13)\end{array}$ & $\begin{array}{c}\text { Model } 3 \\
\text { Sociodemographic } \\
\text { Characteristics, Culture, } \\
\text { and Sexual Behavior } \\
(d f=17)\end{array}$ & $\begin{array}{l}\text { Model } 4 \\
\text { Full Model } \\
(d f=20)\end{array}$ \\
\hline \multicolumn{5}{|l|}{ Sexual initiation and behavior } \\
\hline Menarche at age 11 or younger & & & 0.63 & 0.55 \\
\hline First intercourse < age 16 & & & $4.16^{*}$ & 3.91 \\
\hline $2+$ sex partners last 12 months & & & $8.37 * *$ & $10.19 * *$ \\
\hline Intercourse $4+$ times per week & & & $0.16^{*}$ & $0.09 *$ \\
\hline \multicolumn{5}{|l|}{ Contraceptive behavior } \\
\hline Ever used $3+$ modern methods & & & & 3.79 \\
\hline 1+ unintended pregnancies & & & & 1.58 \\
\hline Duration of current pill use $<7$ months & & & & $11.76 * * *$ \\
\hline$F$ & 1.59 & 2.66 & 4.55 & 3.56 \\
\hline Probability $>F$ & .187 & .015 & .0001 & .003 \\
\hline
\end{tabular}

a. Respondent is single (no spouse or partner is included in this living arrangement). $* p \leq .05 . * * p \leq .01 . * * * p \leq .001$. 
Table 4. Odds Ratios for Direct Relationships Between the Significant Cultural Covariates $(N=703)$

\begin{tabular}{|c|c|c|c|c|c|}
\hline & $\begin{array}{l}\text { Spanish } \\
\text { Interview }\end{array}$ & $\begin{array}{l}\text { Prefers Stay-at- } \\
\text { Home Mother }\end{array}$ & $\begin{array}{c}\text { Prefers Male- } \\
\text { Centered Workplace }\end{array}$ & Roman Catholic & $\begin{array}{l}\text { Attends Services } \\
\text { 1+ Times per Week }\end{array}$ \\
\hline \multicolumn{6}{|c|}{ Sociodemographic characteristics } \\
\hline \multicolumn{6}{|l|}{ Age } \\
\hline 15 to 19 & - & - & 2.41 & 0.37 & 0.18 \\
\hline 20 to 24 & 0.95 & 1.44 & 1.44 & $0.40 *$ & 1.12 \\
\hline 25 to 44 (reference) & 1.00 & 1.00 & 1.00 & 1.00 & 1.00 \\
\hline High school education & $0.04 * * *$ & 0.61 & 0.61 & 1.24 & 1.69 \\
\hline Lives in nonfamily household & $3.51 * * *$ & 1.86 & 1.86 & 0.40 & 0.83 \\
\hline Mexican origin & 1.44 & 2.24 & 2.24 & 0.95 & 1.41 \\
\hline \multicolumn{6}{|l|}{ Hispanic culture } \\
\hline Interviewed in Spanish & & 1.02 & 1.02 & 4.81 & 1.69 \\
\hline Stay-at-home motherhood & 2.64 & 1.34 & 1.35 & 0.60 & 0.84 \\
\hline Male-centered workplace & 1.06 & - & & 0.83 & 0.66 \\
\hline \multicolumn{6}{|l|}{ Religion } \\
\hline Catholic & 1.50 & 0.92 & 0.92 & & $15.53 * *$ \\
\hline Protestant & 0.70 & 1.48 & 1.48 & & $42.82 * * *$ \\
\hline Other & - & & - & & 7.16 \\
\hline Atheist/agnostic & 1.00 & 1.00 & 1.00 & & 1.00 \\
\hline \multicolumn{6}{|l|}{ Attendance of services } \\
\hline Never & 1.00 & 1.00 & 1.00 & 1.00 & \\
\hline 1 to 3 times a month or less & 2.03 & 1.52 & 1.52 & $10.77 * * *$ & \\
\hline Once a week or more & 3.65 & 1.02 & 1.02 & $4.22 *$ & \\
\hline$F$ & 16.86 & 1.66 & 0.92 & 2.25 & 2.03 \\
\hline Probability $>F$ & .001 & .146 & .536 & .042 & .062 \\
\hline
\end{tabular}

NOTE: Covariates with cells containing zero were omitted from logistic regression models. 
Table 5. Odds Ratios for Direct Relationships Between the Significant Covariates of Sexual and Contraceptive Behavior $(N=703)$

\begin{tabular}{|c|c|c|c|c|}
\hline & $\begin{array}{c}\text { First Intercourse } \\
\text { < Age } 16\end{array}$ & $\begin{array}{c}2+\text { Sex Partners } \\
\text { in Prior Year }\end{array}$ & $\begin{array}{c}\text { Intercourse } \\
\text { 4+ Times per Week }\end{array}$ & $\begin{array}{l}\text { Duration of Current } \\
\text { Pill Use }<7 \text { Months }\end{array}$ \\
\hline \multicolumn{5}{|l|}{ Sociodemographic characteristics } \\
\hline \multicolumn{5}{|l|}{ Age } \\
\hline 15 to 19 & $4.86 * *$ & $3.53 * * *$ & 2.69 & 0.28 \\
\hline 20 to 24 & 0.85 & 1.89 & 0.18 & 0.88 \\
\hline 25 to 44 (reference) & 1.00 & 1.00 & 1.00 & 1.00 \\
\hline High school education & $0.18 * * *$ & $0.21 * * *$ & 0.36 & 0.79 \\
\hline Lives in nonfamily household & 0.59 & $10.95 * * *$ & 2.26 & 0.48 \\
\hline Mexican origin & 1.58 & 0.77 & 2.50 & 0.70 \\
\hline \multicolumn{5}{|l|}{ Hispanic culture } \\
\hline Interviewed in Spanish & $0.05 * * *$ & $0.54 *$ & 0.18 & 1.61 \\
\hline Stay-at-home motherhood & 0.30 & 0.26 & 0.46 & 0.51 \\
\hline Male-centered workplace & 0.87 & 1.12 & 0.71 & 3.06 \\
\hline \multicolumn{5}{|l|}{ Religion } \\
\hline Catholic & 0.25 & 0.42 & 3.34 & $0.10^{*}$ \\
\hline Protestant & 0.45 & 0.56 & 1.53 & $0.06^{*}$ \\
\hline Other & $0.05 * *$ & 1.91 & - & 3.18 \\
\hline Atheist (reference) & 1.00 & 1.00 & 1.00 & 1.00 \\
\hline
\end{tabular}


Attendance of services

Never (reference)

1 to 3 times a month or less

Once a week or more

1.00

0.50

1.00

1.00

0.42

1.00

Sexual behavior

Menarche < age 12

First intercourse < age 16

$2+$ sex partners last $12 \mathrm{~m}$

1.00

$0.11 * *$

$0.18 * *$

0.63

Intercourse 4+ times/week

1.07

0.32

$0.08 *$

1.01

Contraceptive behavior

0.51

0.26

1.34

1.13

0.56

2.13

$1+$ unintended pregnancy

0.32
0

F

Probability $>F$

1.57

1.79

1.60

NOTE: Covarates with cells containing zero were omitted from logistic regression models.

$* p \leq .05 . * * p \leq .01 . * * p \leq .001$. 
multiple sex partners. Due to these cell sizes of zero, the sample size was necessarily reduced by 82 (unweighted) observations. As a result of this, a stratum with only one primary sampling unit was detected, and the design-based logistic regression could not be used.

No direct relationships between the sociodemographic or cultural variables and frequency of intercourse were detected. Finally, the odds of Catholics and Protestants reporting short duration of current pill use were significantly lower than those of other religious affiliations ( $\mathrm{OR}=0.10$ and 0.06 , respectively). This suggests that Catholic affiliation and Protestant affiliation have small indirect effects on inconsistent use through their inverse association with duration of pill use.

\section{DISCUSSION}

We undertook this analysis to expand on the previous work of Peterson et al., who found that Hispanic pill users had significantly higher rates of inconsistent use than nonHispanics. ${ }^{2}$ Using the same data, we limited the analysis to Hispanic women and added variables that we thought reflected cultural values characteristic of Hispanic subgroups living in the United States. Was this expanded analysis worth the effort? We believe the answer is yes.

Culture and Inconsistent Oral Contraceptive Use. When our indicators of Hispanic culture were included, the regression showed a good fit to the data, and the effects of gender role attitudes and organizational religiosity significantly improved the explanatory strength of the multivariate analysis. These indicators also had both direct and indirect effects on inconsistent use of oral contraceptives. In particular, the effects of culture on inconsistent use among this sample of Hispanic women was accentuated by primary use of the Spanish language (i.e., the NSFG-V was administered in Spanish).

The odds of inconsistent pill use among those interviewing in Spanish were more than four times higher than among those interviewing in English. Table 4 indicates respondents without a high school education and those living with nonfamily members were more likely to have had the Spanish interview. But Table 4 also reveals that use of Spanish as a primary language is not a significant factor explaining frequent sexual intercourse or short duration of pill use. To explicate the effects of Spanish, we restricted the full regression model to respondents interviewed in English to see whether the effects of any covariates were modified (results not shown).

With the Spanish interviewees removed from the analysis, the significant effects of gender role attitudes were erased, as was the effect of church attendance. In other words, without the 155 respondents using the Spanish interview, the cultural variables fail to contribute any explanatory strength to the model; primary use of Spanish appeared to trigger the significant effects of the cultural variables on inconsistent pill use. This finding supports the idea that low acculturation reinforces attitudes or beliefs that are constraints to contraceptive use. This, in turn, may work against a woman's ability to effectively negotiate contraceptive use with a male partner. Limited English use may also be a barrier to access the mainstream health system. Thus, among this sample of Hispanic women, primary use of Spanish reflected more traditional gender role attitudes, and these attitudes were significantly associated with inconsistent pill use. 
Although this interpretation is based on a single indicator (primary language) to reflect acculturation, it nonetheless makes a useful contribution to the literature on culture and contraception. Specifically, Unger and Molina ${ }^{14}$ investigated the relationship between acculturation and the intention to use contraception among a convenience sample of Hispanic women. They found that women who were at a moderate level of acculturation expressed less certainty about their ability to use contraception consistently during the next 6 months than did their unacculturated counterparts. This suggests that the effects of culture on contraceptive intention are different from the effects of culture on contraceptive behavior. More research investigating these potential differences would go a long way toward understanding the relationship between culture and contraception.

Hispanic Model Versus General Population Model. Several findings from this analysis of inconsistent pill use were similar to those of Peterson et al. ${ }^{2}$ For example, short duration of pill use was the strongest predictor in the earlier analysis, and it has proven to be the strongest in this analysis as well. Peterson et al. found that education had no direct effect on inconsistent use, whereas our findings suggest that education has an indirect effect that operates through primary use of Spanish. The earlier study found that unintended pregnancy was associated with inconsistent oral contraceptive use, but in this study, unintended pregnancies had no effect.

Finally, we found that frequency of intercourse appeared to be a protective factor against inconsistent pill use. Whereas this variable was not significant in the Peterson et al. study, a decision was made to adjust the measure in the current analysis to reflect very frequent intercourse (i.e., four or more times per week), as opposed to frequent intercourse (once a week or more) in the earlier study. This measurement difference is important because of the possibility that routinely high levels of intercourse might increase the day-to-day salience of taking the pill on time.

Two variables that were significant in this analysis were not present in the earlier study: living arrangement and number of sex partners in the past 12 months. Hispanic women who were living alone or with friends, roommates, or other nonfamily members were less likely to have used the pill inconsistently. Although the protective effects of such living arrangements are unclear, it could be that these women are not in long-term sexual relationships and are thus more cautious about unintended pregnancy. More research is needed to investigate whether the effect of living arrangement is unique among Hispanic women or is the same for non-Hispanic women as well. Having multiple sex partners increased the odds of missing pills, and we showed that not one of the Spanish language respondents reported more than one recent sex partner. This is consistent with studies that relate acculturation to high-risk sexual behavior. ${ }^{50}$

Hispanics represent one of the fastest growing segments of America's population. With this rapid growth comes the possibility that traditionally strong family ties and religious belief systems among Hispanics in the United States begin to erode in a process of acculturation. Does this process imply that the Hispanic-Anglo differential in the consistency of oral contraceptive use will disappear? A more complete evaluation of the role of Hispanic culture in this dynamic involves identifying those constructs that are uniquely salient to Hispanics living in the United States and monitoring the endurance of those constructs over time. We hope that such future research will overcome the limitations encountered here. First, nationally representative surveys like the NSFG need to include more sensitive measures of culture (e.g., acculturation scales). Second, although the 
equations shown here had adequate statistical power,* larger subsamples of minority populations would lead to more stable estimates. Third, the measurement of inconsistent oral contraceptive use should be more precise.

\section{IMPLICATIONS FOR PRACTICE}

Despite these limitations, the findings discussed here have important implications for practice. Reproductive health providers should recognize the heterogeneity of sexual and contraceptive behaviors among Hispanic women in the United States. In particular, although one NSFG-based study identified Hispanics as a single population at especially high risk of using pills inconsistently, we have shown that within that population, the risk of inconsistent use varies significantly according to a number of factors. For example, preference for Spanish language might signal an increased risk of inconsistent pill use. Consequently, provider competence to address language barriers appears to offer many clinical benefits with respect to appropriately tailoring health education messages, especially regarding the importance of the family and traditional family values. Providers should counsel new oral contraceptive use clients about the importance of daily compliance, as this group (both Hispanic and non-Hispanic) is at especially high risk of missing two or more pills. Finally, having multiple recent sex partners substantially increased the odds of inconsistent use. This finding should reinforce for providers the usefulness of documenting sexual histories from family planning and reproductive health clients.

Culture is obviously more complex than gender roles, religion, and language. Future research might further explore how culture relates to resiliency or to factors that protect against exposure to sexual and contraceptive risk. Such research has informed more effective interventions with respect to Hispanic youth educational achievement $t^{51-53}$ and could be more rigorously applied to pregnancy prevention programs.

\section{References}

1. Abma J, Chandra A, Mosher W, Peterson L, Piccinino L: Fertility, family planning, and women's health: New data from the 1995 National Survey of Family Growth. National Center for Health Statistics. Vital Health Stat 23(19), 1997.

2. Peterson LS, Oakley D, Potter LS, Darroch JE: Women's efforts to prevent pregnancy: Consistency of oral contraceptive use. Family Plan Perspect 30:19-23, 1998.

3. Jemmott III J, Jones J: Social psychology and AIDS among ethnic minority individuals: Risk behaviors and strategies for changing them, in Pryor J, Reeder G (eds.): Social Psychology of HIV Infection. Hillsdale, NJ, Lawrence Erlbaum, 1993, pp. 83-224.

4. Villarruel A: Moving towards cultural competence? Capsules Comments Pediatr Nurs 1:18-25, 1995.

5. The National Program Coalition of Hispanic Health and Human Services Organization (COSSMHO): Meeting the health promotion needs of Hispanic communities. Am J Health Promot 9(4):300-311, 1995.

6. Unger JB, Molina GB: Desired family size and attitudes toward childbearing among Latinas of low socioeconomic status. Family Plan Perspect 29:284-287, 1997.

*If we assume a small effect size (.20) and a confidence level of 95\%, our unweighted sample of 164 equates to a power level of approximately .74. This is below the general standard of .80 as discussed by Cohen \& Cohen (1983). With a medium effect size (.30) power increases to .97. 
7. Day RD: The transition to first intercourse among racially and culturally diverse youth. $J$ Marriage Fam 54:749-762, 1992.

8. Durant RH, Seymore C, Pendergrast R, Beckman R: Contraceptive behavior among sexually active Hispanic adolescents. J Adolesc Health Care 11:490-496, 1990.

9. Fennelly DK, Ortiz V: Childbearing among young Latino women in the United States. Am J Public Health 77(1):25-28, 1987.

10. Forrest JD, Frost JJ: The family planning attitudes and experiences of low-income women. Family Plann Perspect 28(6):246-255, 1996.

11. Torres S, Villarruel AM: Health risk behaviors for Hispanic women. Ann Rev Nursing Res 13:293-319, 1995

12. Meleis AI, Isenberg M, Koerner JE, Bernadine L, Stern P: Diversity, Marginalization and Culturally Competent Health Care Issues in Knowledge Development. Washington, DC, American Academy of Nursing, 1995.

13. Novello AC: Report of the Surgeon General's National Workshop on Hispanic/Latino Health, 1992.

14. Unger JB, Molina GB: Acculturation and attitudes about contraceptive use among Latina women. Health Care Women Intern 21:235-249, 2000.

15. Cuellar I, Arnold B, Maldonado R: Acculturation rating scale for Mexican Americans-II: A revision of the original ARSMA scale. Hispanic J Behav Sci 17(3):275-304, 1995.

16. Norris AE, Ford K, Bova C: Psychometrics of a brief acculturation scale for Hispanics. Hispanic J Behav Sci 18(1):29-38, 1996.

17. Marin BV, Marin G: Predictors of condom accessibility among Hispanics in San Francisco. Am J Pub Health 82(4):592-595, 1992.

18. Sabogal F, Faigeles B, Catania JA: Multiple sexual partners among Hispanics in high-risk cities: Data from the National AIDS Behavioral Surveys. Family Plan Perspect 25(6):257-262, 1993.

19. Peragallo N: Latino women and AIDS risk. Public Health Nurs 13:217-222, 1996.

20. Marin G, Sabogal F, Marin B, Otero-Sabogal R, Perez-Stable EJ: Development of a short acculturation scale for Hispanics. Hispanic J Behav Sci 9(2):183-205, 1987.

21. Jones ME, Bond ML, Gardner SH, Hernandez MC: Acculturation level and family planning patterns of Hispanic immigrant women. MCN, Am J Maternal/Child Nurs 27(1):26-32, 2002.

22. Marin G, Marin BV: Research With Hispanic Populations. Newbury Park, CA, Sage, 1991.

23. Kelly JE, Mosher WD, Duffer AP, Kinsey SH: Plan and operation of the 1995 National Survey of Family Growth. National Center for Health Statistics. Vital Health Stat 1(36), 1997.

24. Casas JM, Wagenheim BR, Banchero R, Mendoza-Romero J: Hispanic masculinity: Myth or psychological schema meriting clinical consideration. Hispanic J Behav Sci 16:315-331, 1994.

25. Purdy JK, Arguello D: Hispanic familism in caretaking of older adults: Is it functional? $J$ Gerontol Soc Work 19(2):29-43, 1992.

26. Kaplan CP, Erickson PI, Stewart SL, Crane LA: Young Latinas and abortion: The role of cultural factors, reproductive behavior, and alternative roles to motherhood. Health Care Women Intern 22:667-689, 2001.

27. De Anda D, Becerra RM, Fielder P: Sexuality, pregnancy, and motherhood among MexicanAmerican adolescents. J Adolesc Res 3:403-411, 1988.

28. Smith E, McGill L, Wait R: Hispanic adolescent conception and contraception profiles: A comparison. J Adolesc Health Care 8:352-355, 1987.

29. Smith E, Weinman M: Cultural implications for public health policy for pregnant Hispanic adolescents. Health Values 19:3-9, 1995.

30. Hodges BC, Leavy J, Swift R, et al: Gender and ethnic differences in adolescents' attitudes toward condom use. J School Health 62:103-106, 1992.

31. Padilla A, Baird T: Mexican-American sexuality and sexual knowledge: An exploratory study. Hispanic J Behav Sci 13:95-104, 1991.

32. Villarruel A: Cultural influences on the sexual attitudes, beliefs, and norms of young Latina adolescents. J Soc Pediatr Nurs 3(2):69-80, 1998. 
33. Christopher E, Johnson D, Roosa M: Family, individual, and social correlates of early Hispanic adolescent sexual expression. J Sex Res 30:54-61, 1993.

34. Meleis AI, Douglas M, Eribes C, Shih F, Messias D: Employed Mexican women as mothers and partners: Valued, empowered and overloaded. J Adv Nurs 23:82-90, 1996.

35. Unger JB, Molina GB: Educational differences in desired family size and attitudes toward childbearing in Latina women. Popul Environ 20:343-351, 1999.

36. Scanzoni J: Sex Roles, Women's Work, and Marital Conflict: A Study of Family Change. Lexington, MA, Lexington Books, 1978.

37. Gerbing DW, Hamilton JG: Validity of exploratory factor analysis as a precursor to confirmatory factor analysis. Structural Equation Modeling 3:62-72, 1996.

38. Stavans I: The Hispanic Condition: Reflections on Culture and Identity in America. New York, HarperCollins, 1995.

39. Durant RH, Pendergrast R, Seymore C: Sexual behavior among Hispanic female adolescents in the United States. Pediatrics 85:1051-1058, 1990.

40. Pena M, Frehill LM: Latina religious practice: Analyzing cultural dimensions in measures of religiosity. J Scientific Study Religion 37(4):620-635, 1998.

41. Potter L, Oakley D, de Leon-Wong E, Cañamar R: Measuring compliance among oral contraceptive users. Fam Plann Perspect 28:154-158, 1996

42. Soler H, Quadagno D, Sly DF, Riehman KS, Eberstein IW, Harrison DF: Relationship dynamics, ethnicity and condom use among low-income women. Family Plann Perspect 32(2):82$88,101,2000$.

43. Durant RH, Jay MS, Linder SW, et al: Influence of psychosocial factors on adolescent compliance with oral contraceptives. J Adolesc Health Care 5:1-6, 1984.

44. Norris AE, Ford K: Beliefs about condoms and accessibility of condom intentions in Hispanic and African American youth. Hispanic J Behav Sci 14(3):373-382, 1992.

45. Rosenberg MJ, Waugh MS, Meehan TE: Use and misuse of oral contraceptives: Risk indicators for poor pill taking and discontinuation. Contraception 51(5):283-288, 1995.

46. Mosher WD, Pratt WF: Contraceptive use in the United States, 1973-1988. Adv Data Vital Health Stat 182, 1990.

47. Santelli JS, Warren CW, Lowry R, Sogolow E, Collins J, Kann L, Kaufmann RB, Celentano DD: The use of condoms with other contraceptive methods among young men and women. Fam Plann Perspect 29(6):261-267, 1997.

48. Potter FJ, Iannacchione VG, Mosher WD, Mason RE, Kavee JD: Sample design, sampling weights, imputation, and variance estimation in the 1995 National Survey of Family Growth. National Center for Health Statistics. Vital Health Stat Ser. 2(124), 1998.

49. StataCorp: Stata Statistical Software: Release 6.0. College Station, TX, Stata Corporation, 1999.

50. Peragallo N: Latino women and AIDS risk. Public Health Nurs 13(3):217-222, 1996.

51. Gordon K: Resilient Hispanic youth's self-concept and motivational patterns. Hispanic J Behav Sci 18(1):63-73, 1996.

52. Mehan HI, Villanueva LH, Lintz A: Constructing School Success: The Consequences of Untracking Low-Achieving Students. New York, Cambridge University Press, 1996.

53. Pulido JA: A high school program for "at risk" Latino youth: mujeres y hombres nobles (honorable men and women). Am Second Educ 23:10-12, 1995. 